\title{
HIIT and Resistance Training Effects on Learning-related Outcomes in Underserved School Children
}

\author{
Jessica Peacock, PhD 1, ${ }^{,}$, Kevin Finn, EdD ${ }^{2}$, April Bowling, ScD ${ }^{3}$ \\ ${ }^{1}$ Department of Exercise and Rehabilitation Science, School of Health Sciences, Merrimack College, North Andover, MA, USA \\ 2 School of Nursing and Health Sciences, Colby-Sawyer College, New London, NH, UK \\ ${ }^{3}$ Department of Nutrition and Public Health, School of Health Sciences, Merrimack College, North Andover, MA, USA. \\ *Corresponding author Email: peacockj@merrimack.edu
}

DOI: https://doi.org/10.34256/ijpefs2211

Received: 21-09-2021, Revised: 03-01-2022; Accepted: 16-01-2022; Published: 25-01-2022

Abstract: Research has demonstrated associations between differing modalities of physical activity (PA) and behavioral and learning outcomes; however, little evidence exists in real world settings. To evaluate the effects of embedding high intensity interval training (HITT) and resistance training (RT) into physical education (PE) curriculum on PA, academic performance, and behavior in youth attending urban schools. Forty boys and 30 girls; ages 8-10 yrs. enrolled in an expanded public school supplemental learning program were assigned into one of three conditions using a pragmatic trial design: standard PE curriculum $(n=23), \operatorname{HITT}(n=25)$, and RT ( $n=22)$. PA was measured using accelerometers; math achievement scores were conducted at baseline and postintervention using the Math Knowledge Assessment (MKA); behavior was assessed using the Abbreviated Conners Rating Scale (ACRS) daily. Participation in HITT resulted in 1.86 additional vigorous PA minutes $(p=0.04)$ and 0.76 additional very vigorous PA minutes $(\mathrm{P}=0.02)$ per session, but was not associated with increased moderate PA minutes compared to the control group. RT PA outcomes did not differ from regular PE. Participating in HIIT, but not RT, was associated with a 1.82-point improvement in math test scores compared to those in the same grade in the standard PE group $(p=0.02)$. No group assignment was associated with behavioral ratings. Embedding HITT within PE has potential for improving vigorous PA levels and may affect learning outcomes in urban youth. This is consistent with prior studies which show how short bouts of intense exercise can improve cognitive outcomes.

Keywords: Physical Activity, Low-Income Communities, High Intensity Interval Training, Resistance Training, Health Promotion

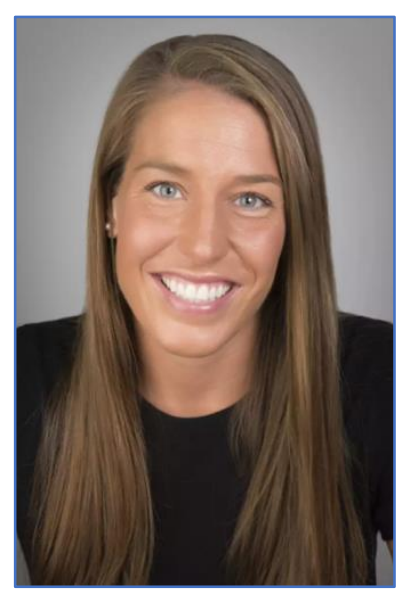

Dr. Peacock is an Assistant Professor in the School of Health Sciences in the Department of Exercise \& Rehabilitation Sciences at Merrimack College. Her research and professional writing focus on pedagogical strategies and tools to enhance student learning in integrated STEM courses. Jessica also focuses on enhancing physical activity and academic achievement in children through the implementation of a national program called Active Science, which integrates physical activity, technology and academic achievement in school-age children.
Other areas of her research focus on the role of fluid balance on performance in male and female athletes.

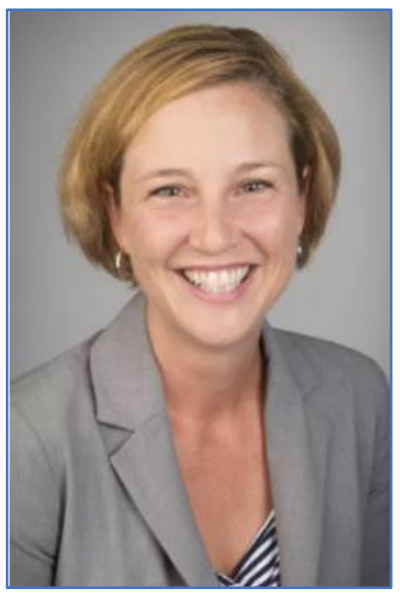

Dr. Bowling is an Assistant Professor of Health Science in the Department of Nutrition and Public Health at Merrimack College. Her research is focused on nutrition and exercise interventions that elicit sustained changes in behavioral health among children with neurodevelopmental and affective disorders such as autism, attention deficit hyperactivity disorder (ADHD) and anxiety. She is also 
involved in research on effects of ADHD and stimulant use on BMI trajectory in late adolescence. Other research interests include exploring the role of physical activity in children's neuropsychological development, and complex systems model development to aid in the design and evaluation interventions

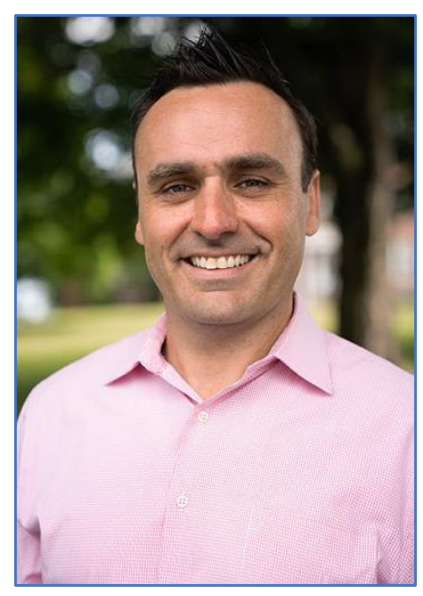

Dr. Kevin E. Finn is Dean and Professor of the School of Nursing and Health Sciences and Director of Clinical Partnerships at ColbySawyer College. He was previously the Associate Dean and Professor for the School of Health Sciences at Merrimack College. In this role, he created and oversaw initiatives on clinical and internship placements, curriculum development, program implementation, and research outcomes that were instrumental in the growth of Health Sciences at Merrimack College. His research interest focuses on physical activity promotion and STEM learning in children. He has worked closely with school and after-school programs to implement effective strategies to increase physical activity and improve academic performance in a national program called Active Science. Kevin also focuses on the effects of pedagogical tools utilized in the college classroom to promote student learning and perceptions in science in addition to conducting clinical research which examines the effects of biomechanical factors on runners.

\section{Introduction}

Participation in regular physical activity (PA) and fitness are associated with numerous physical and mental health benefits in youth $[1,2]$. Such benefits include improvements in body composition, physical capacity, behavioral regulation, self-esteem, self-worth, anxiety, depression, sleep and overall health related indicators (i.e. blood pressure, insulin sensitivity, lipid profile, and C-reactive protein) [1, 3-4]. Research also suggests that increased participation in PA and achieving the recommended PA guidelines are linked to enhanced physical fitness, brain structure, cognitive function and academic performance [1]. However, despite the positive physical and health-related benefits associated with high levels of physical fitness, less than $20 \%$ of youth are currently meeting or exceeding the recommended daily 60 minutes of PA, most of which should be moderate to vigorous physical activity (MVPA) [5]. Concomitant with the reduction is daily physical activity is a decrease muscular fitness (i.e., muscular strength, muscular power, and muscular endurance) in modern day youth [6]. Importantly, developing healthy PA behaviors that promote MVPA and muscular fitness in youth is associated with less risk of chronic disease and health disparities such as obesity and type 2 diabetes across the life course, conditions which disproportionately affect low-income and minority populations [7]. Currently, school-aged children achieve an average of 30 MVPA minutes daily [5], and youth living in urban environments and attending under-resourced schools are at higher risk of inadequate MVPA [5].

Physical education (PE) programming is the primary vehicle associated with promoting $\mathrm{PA}$ in a school setting, yet both total PA minutes and highintensity PA within many PE lessons are generally low, especially in youth attending under-resourced public schools [8]. Low-income urban school settings often face inadequate funding, facilities, equipment, and personnel challenges that lead to infrequent and under-resourced PE classes [5]. Although intervention programs and policies to improve PA duration and intensity in PE programming have been developed and implemented, policies vary considerably across school districts [9]. School policies related to PE programming including frequency, duration, and equipment, significantly impact opportunities for youth to achieve health benefits and PA guidelines, particularly in public schools in under-resourced communities [8]. While increasing the duration and frequency of $P E$ programming would be ideal, this option may not feasible given budgetary, scheduling, or facilities constraints. Therefore, developing innovative, time efficient, and scalable strategies that integrate both health-related (aerobic fitness, muscular strength, muscular endurance, flexibility) and skill-related (speed, power, coordination, reaction time, agility) components of fitness to promote improvements in MVPA, muscular fitness and academic success is essential to close PA disparities and optimize the behavioral and learning benefits of exercise in historically underserved populations $[4,6]$.

High-intensity interval training (HITT) has emerged as a strategy to provide physical and mental health benefits among youth populations $[1,10]$. One study exploring the effects of HITT programs on cognitive and mental health outcomes in adolescents reported improvements in executive function and 
psychological well-being in response to HITT-focused aerobic-specific exercises. With HITT, the exercise intensity is varied at fixed intervals during a single bout of exercise (i.e. intervals from $\leq 45 \mathrm{~s}$ to $2-4 \mathrm{~min}$ of high intensity exercise interspaced by short rest periods, or intervals from 10 s to $20-30$ s interspaced by prolonged rest periods [1]. The main purpose of HITT is to experience equivalent benefits of exercise in a short period of time compared to more traditional and longer aerobic training.

Resistance training (RT) uses different modes of training with a wide range of resistance loads from body weight to barbells; it is designed to enhance muscular strength, muscular power, and local muscular endurance. While less researched than HIIT in relation to effects on cognition and learning, studies have indicated that RT influences the development of gross and fine motor skills in children and adolescents, which are in turn linked to increased neural network development and activation [11]. For example, one study explored the effects of aerobic and resistance exercise on executive function, and concluded that improvements in executive function were induced by an acute bout of exercise regardless of whether the mode was aerobic or resistance [12]. Another study has found that integrated 15 minutes of functional integrative training into traditional PE curricular was associated with improvement in both health and skill related components of fitness [4].

Despite evidence supporting potential associations between HIIT, RT, and cognitive and learning benefits, more research is needed to evaluate these relationships in real world settings such as schools $[1,10]$. Therefore, the objective of this pragmatic trial was to evaluate the feasibility and preliminary efficacy of implementing acute HITT and RT programming into PE classes to increase PA and improve academic and behavioral outcomes in Lawrence, Massachusetts, youth enrolled in the Accelerations Academies Program (AAP). The AAP is a week-long academic program funded by the Sontag Prize in Urban Education and is designed to provide additional academic support to small groups of youth living in low-income communities. Lawrence, Massachusetts, has a population of just over 80,000 , approximately $80 \%$ of whom are Hispanic; $21 \%$ live in poverty [13]. The primary goal of AAP is to afford the district's lowest-performing students the opportunity to engage in 25-30 additional hours of instruction in one subject area (equivalent to an additional month of direct in-school instruction). This extended learning time provides targets, data-driven support to help students in class and prepare them for standardized testing. The AAPs in Lawrence, Massachusetts, take place during the school district's February and April school vacation weeks. Over 2,000 students across K-8 LPS, the High School Learning Center, and the LHS campus attend the AAP; over 250 teachers participate. During the AAP, students engage in approximately five hours of content instruction focused on English language arts (ELA), science or mathematics, and 60 min of enrichment per day for the week-long program which typically focuses on $\mathrm{PE}$, art, or music. In the current study, the AAP focused on mathematical instruction with PE programming as the enrichment period; therefore, the specific aims of this study were as follows:

1. to evaluate the effects of embedding HITT and $\mathrm{RT}$ programming in established PE curriculum on PA outcomes;

2. to determine whether incorporating HITT and RT activities in PE programming is associated with improvements in math achievement scores in third and fourth grade students enrolled in the AAP; and

3. to assess whether implementing HITT and RT programming affects behavioral ratings of third and fourth graders enrolled in the AAP.

\section{Materials and Methods}

\subsection{Design and Setting}

This study was designed as a non-randomized control design to be conducted within the Lawrence Public School District. All study protocols and materials were approved by both the Merrimack College and Lawrence Public Schools (LPS) Institutional Review Boards. In partnership with the Merrimack Valley YMCA, students attending the AAP at one Lawrence elementary school were selected to participate in the study. Within that school, six classrooms (three $3^{\text {rd }}$ and three $4^{\text {th }}$ grades) were assigned to either an intervention condition (acute bout of HITT or RT programming followed by established PE curriculum) or a control condition (established PE curriculum) for 60minutes per day during the week-long AAP. Parents and study participants provided written informed consent/assent to participate in the study.

\subsection{Main Outcomes}

PA outcomes examined included total minutes of PA, minutes of PA and MVPA as a percentage of 
available class time, and minutes of moderate, vigorous, and very vigorous PA. Outcomes in math achievement were measured using the Math Knowledge Assessment (MKA), which was composed of 12 questions assessing math content contained in the curriculum during the AAP. The MKA is not a validated instrument but is used for evaluation by the APP. It uses selected questions from Massachusetts curriculum assessments by grade level, which were in turn mapped to the curriculum presented during the AAP. Students' behaviors were measured daily via the validated Abbreviated Conners Ratings Scale (ATRS), a 10 -item inventory using a cutoff score of 15 [14].

\subsection{Participants}

Study participants $(n=70)$ were students in grades 3 and 4 (age 8-10 yrs.) attending the AAP at one participating school. Participants were $45.7 \%$ third graders and $42.8 \%$ female. There were six total classrooms at this participating school. Three classes were $3^{\text {rd }}$ graders and three of which were $4^{\text {th }}$ graders; each classroom had a head teacher and an assistant teacher. If a student was absent for either the pre- or post- MKA assessment, they were excluded from the analyses.

\subsection{Data Collection}

To collect PA outcomes (total minutes of MVPA, minutes of moderate, vigorous, and very vigorous PA) students in both intervention groups and the control group wore a research-grade accelerometer positioned on their right hip (Actigraph (Wgt3X-BT) (Pensacola, Fla) for the daily 60-minute PE enrichment period. Research assistants fitted the accelerometers to students upon arrival at the gymnasium for their 60minutes of PE enrichment. Throughout the week-long program, students were assigned to an intervention group (HITT or RT programming) or the control group (established PE curriculum). The programming for the intervention group was developed by the research team and taught by the PE teacher; the same PE teacher taught the PE curricula to the control condition. At the end of the enrichment period, participants removed the devices. Accelerometer data were downloaded at the end of the week; Freedson (youth) cutoffs were used to determine time spent in MVPA [15]. To measure behavioral outcomes on each student, the six classroom teachers completed the ATRS daily for each student in their assigned class. MKA scores were administered pre- (immediately upon arrival on the first day of the program) and post- intervention (end of the day on the last day of the program).

\subsection{Intervention}

To maintain consistency across all conditions, students assigned to the intervention (HITT or RT programming) and the control groups completed the same 5-10-minute warm-up and cool-down, both which aligned with the PE curriculum. Following the warm-up, the control group engaged in an established PE curriculum for approximately 40-45 minutes before completing the 5-10-minute cool down. The activities focused on standard PA competencies appropriate for $3^{\text {rd }}$ and $4^{\text {th }}$ graders. The intervention conditions were completed in pairs, with one student undertaking the 'work' phase, while their partner completed the 'rest' phase. Students assigned to HITT programming completed 4 consecutive days of HITT ( $9 \mathrm{~min} / \mathrm{session}$; $30 \mathrm{sec}$ on:30 sec off) followed by $30 \mathrm{~min}$ of standard PE curriculum and a 5-10-minute cool down. HITT exercises primarily involved gross motor cardiorespiratory exercises (e.g. running, skipping, jumping jacks, burpees, scissor jumps, mountain climbers). Students assigned to RT programming completed 4 days of RT ( 3 sets/10-12 reps for 3 exercises/session) followed by $30 \mathrm{~min}$ of standard PE and a 5-10-minute cool down. RT exercises aimed to enhance muscular strength and primarily involved isometric, isokinetic, and isotonic strength exercises (e.g. push-ups, sit ups, planks, lunges, squats, wall sits, and resistance band walks).

\subsection{Statistical Analysis}

All quantitative analyses were performed using STATA 13. Since students were assigned to treatment groups by classroom and grade, analyses were stratified by grade to prevent confounding by age and developmental status. This approach ensured that $3^{\text {rd }}$ graders in the treatment condition were only compared to $3^{\text {rd }}$ graders in the control condition. The same approach was applied to $4^{\text {th }}$ graders. Summary statistics were used to report demographics and baseline math scores by group. Baseline multiple comparisons of math scores by group were made using the Bonferroni correction. Differences were not assessed for behavioral rating scores or MVPA since no pre-intervention baseline measures could be assessed. Fixed effects linear regression was used to assess relationships between total MVPA, moderate $P A$, vigorous $\mathrm{PA}$, very vigorous $\mathrm{PA}$, and pre-post math score changes and treatment groups; models were run 
both with and without gender, which is a known potential moderator of both PA and math scores, but was not significant when assessed using stepwise regression. Interactions between group and gender were also tested in models. Mixed effects regression was used to assess associations between behavioral rating score and treatment group while controlling for random effects of individual and day.

\section{Results}

Participant characteristics are shown in Table 1. Overall, students averaged 33.1 minutes (11.2 SD) of MVPA per PE class; students in the control group averaged 33.3 minutes (9.0 SD), students in the HIIT group averaged 35.5 minutes (10.0 SD), and students in the muscular strength group averaged 29.7 minutes (14.3 SD).
Results of fixed effects linear regression models evaluating associations between group assignment and PA and math outcomes are shown in Table 2. Participation in HITT predicted 1.86 additional vigorous $P A$ minutes $(p=0.04)$ and 0.76 additional very vigorous $P A$ minutes $(p=0.02)$ per session, but was not associated with increased total MVPA minutes compared to the control group. Students in the control group (PE curriculum only) spent $55 \%$ of available time in MVPA engagement, where students in the HITT intervention group averaged $59 \%$ of available time, and those in the RT intervention group averaged 29.7 minutes of MVPA $49 \%$ of available time.

Participation in RT was not statistically different compared to the control group for any category of PA intensity.

Table 1 Participant Characteristics by Group

\begin{tabular}{|c|c|c|c|c|}
\hline & Control & HITT & Strength & Total \\
\hline Grade $(N)$ & & & & \\
\hline $3^{\text {rd }}$ Grade & 13 & 25 & 0 & 38 \\
$4^{\text {th Grade }}$ & 10 & 0 & 22 & 32 \\
\hline Gender $(N)$ & & & & \\
\hline Boys & 7 & 12 & 11 & 30 \\
Girls & 16 & 13 & 11 & 40 \\
\hline
\end{tabular}

Table 2 Associations between exercise orientation, physical activity, and math change score by grade.

\begin{tabular}{|c|c|c|c|c|c|}
\hline & $\begin{array}{c}\text { Total Min of } \\
\text { MVPA }^{\mathrm{a}}\end{array}$ & $\begin{array}{c}\text { Min of } \\
\text { Moderate PA }\end{array}$ & $\begin{array}{c}\text { Min of } \\
\text { Vigorous PA }\end{array}$ & $\begin{array}{c}\text { Min of Very } \\
\text { Vigorous PA }\end{array}$ & $\begin{array}{c}\text { Math } \Delta \\
\text { Score }\end{array}$ \\
\hline $\begin{array}{l}\text { Independent } \\
\text { Variable }\end{array}$ & \multicolumn{5}{|c|}{$\begin{array}{l}\text { Coefficient } \\
(95 \% \mathrm{CI})\end{array}$} \\
\hline \multicolumn{6}{|l|}{$3^{\text {rd }}$ Graders } \\
\hline $\begin{array}{l}\text { HIIT } \\
\text { Participation }\end{array}$ & $\begin{array}{c}2.98 \\
(-1.15,7.11)\end{array}$ & $\begin{array}{c}0.36 \\
(-3.03,3.75)\end{array}$ & $\begin{array}{c}1.86 \\
(0.04,3.68)\end{array}$ & $\begin{array}{c}0.76 \\
(0.11,1.41)\end{array}$ & $\begin{array}{c}1.82 \\
(0.44,3.21)\end{array}$ \\
\hline Intercept & $\begin{array}{c}32.53 \\
(29.15,35.91)\end{array}$ & $\begin{array}{c}26.38 \\
(23.61,29.16)\end{array}$ & $\begin{array}{c}5.50 \\
(4.01,6.99)\end{array}$ & $\begin{array}{c}0.65 \\
(0.12,1.18)\end{array}$ & $\begin{array}{c}2.44 \\
(1.35,3.54)\end{array}$ \\
\hline \multicolumn{6}{|l|}{$4^{\text {th }}$ Graders } \\
\hline $\begin{array}{l}\text { Muscular } \\
\text { Strength } \\
\text { Participation }\end{array}$ & $\begin{array}{c}-4.28 \\
(-10.16,1.39)\end{array}$ & $\begin{array}{c}-2.75 \\
(-7.75,2.26)\end{array}$ & $\begin{array}{c}-1.50 \\
(-3.60,0.59)\end{array}$ & $\begin{array}{c}-0.13 \\
(-0.53,0.26)\end{array}$ & $\begin{array}{c}0.54 \\
(-1.39,2.46)\end{array}$ \\
\hline Intercept & $\begin{array}{c}34.10 \\
(29.51,38.70)\end{array}$ & $\begin{array}{c}28.83 \\
(24.85,32.81)\end{array}$ & $\begin{array}{c}4.72 \\
(3.06,6.39)\end{array}$ & $\begin{array}{c}0.55 \\
(0.23,0.86)\end{array}$ & $\begin{array}{c}2.29 \\
(0.67,3.91)\end{array}$ \\
\hline \multicolumn{6}{|c|}{$\begin{array}{l}\text { a Physical activity and math change score models are fixed effects linear regression models. Gender } \\
\text { was assessed using stepwise regression and reported in the text where significant. Results are relative } \\
\text { to control group. }\end{array}$} \\
\hline
\end{tabular}


Table 3 Associations between behavioral score and treatment group by grade.

\begin{tabular}{|l|c|}
\hline \multicolumn{2}{|l|}{ Connors Behavioral Rating Scale Score $^{\text {a }}$} \\
\hline Independent Variable & Coefficient $(95 \% \mathrm{CI})$ \\
\hline $3^{\text {rd }}$ Graders & $-1.57(-5.48,2.33)$ \\
\hline HIIT Participation & $15.08(11.89,18.27)$ \\
\hline Intercept & $0.30(-1.72,2.32)$ \\
\hline $4^{\text {th }}$ Graders & $9.71(6.37,13.04)$ \\
\hline Muscular Strength Participation & \\
\hline Intercept & \\
\hline $\begin{array}{l}\text { a Connor score models are repeated measures controlling for random effects of individual and day. } \\
\text { Results are relative to control group. }\end{array}$ \\
\hline
\end{tabular}

Gender was not a significant predictor of any PA outcome except for vigorous and very vigorous PA among $4^{\text {th }}$ graders only; adjusting for gender in those models did not change direction or significance of associations, and no interactions between gender and group assignment were significant.

Among $3^{\text {rd }}$ graders, being assigned to the HIIT participation groups was associated with an additional 1.82-point improvement in math test scores compared to $3^{\text {rd }}$ graders in the control group $(p=0.02)$. Assignment to the muscular strength group among 4th graders was not associated with improved test scores when compared to $4^{\text {th }}$ graders in the control group.

Results of mixed effects regression models evaluating associations between group assignment and behavioral rating scores, controlling for random effects of individual and day, are shown in Table 3. No group assignment was associated with significant changes to behavioral ratings.

\section{Discussion}

School-aged children attending public school systems in low-income, underserved communities are less likely to meet current PA guidelines of at least 60 minutes of MVPA per day, less inclined to engage in PA outside of the traditional school day, and underperform on standardized testing relative to peers in higherincome school systems [16-18]. We explored the efficacy and feasibility of incorporating HITT and RT programming into established $\mathrm{PE}$ curriculum to increase PA engagement, academic, and behavioral outcomes during the AAP focused on mathematic instruction and PE enrichment. The AAP are week-long academic programs designed to provide students in under resourced communities approximately 25 additional hours of individual and group instruction primarily focused on ELA, science or math content to help students prepare for and improve on standardized tests. Combined with additional hours of instruction, students engage in 60-minutes of "enrichment" per day. In the current study, third and fourth grade students attending the AAP at one selected public school in Lawrence, Massachusetts engaged in mathematics focused instruction and PE enrichment throughout the entire duration of the program.

As expected, students participating in HIIT got more high intensity PA compared to those participating in standard PE programming only, while those participating in RT did not. HIIT participation, while short duration, was associated with small significant improvements to math scores relative to students of the same grade level in the standard PE group; this observation is in keeping with previous research showing acute positive impacts of aerobic exercise on learning and cognition [19-21]. Although not statically significant, very small improvements in math assessment scores were also observed in $4^{\text {th }}$ graders assigned to the RT intervention group; thus, we cannot rule out the potential benefits of RT training. A previous study evaluated the efficacy of a school-based intervention program focused on promoting health and skill related components of fitness and concluded, that $\sim 15$ minutes of fundamental integrated training resulted in significant improvements in aerobic capacity, push-ups, flexibility and single leg-hop [6]. Less research has specifically explored solely the effects of RT training on PA and academic outcomes in youth and suggests that RT training is associated with improved musculoskeletal health and motor skill 
development [11]. Therefore, the lack of an association between RT assignment and math scores should be further explored during a longer period, since impacts of chronic RT on cognition via motor skill development would not be apparent over the study's one week period.

With a goal of increasing PA levels during the PE enrichment period throughout the week-long AAP, the established PE curriculum implemented team-based activities to engage students in moderate intensity exercise, increasing the average minute's students spent in MVPA, and decreasing the percentage difference between the HITT and control group. This implementation is important given that established PE curricula typically incorporate various multi-week units focused on various health and skill-related components of fitness, many of which are low aerobic-intensity activities. Low engagement in aerobic activity is associated with lower fitness levels, which may then additionally discourage exercise participation [1]. The current findings suggest that embedding an acute bout of HITT into PE curriculum can increase MVPA levels while also meeting the PE competencies.

Analyses from the ATRS reported no differences in student behavior from baseline and across each day of the program in both $3^{\text {rd }}$ and $4^{\text {th }}$ grade AAP students. However, given that baseline ATRS scores indicated no evidence of behavioral dysregulation in participants, this finding does not rule out the potential benefits on behavior outcomes when incorporating HITT or RT programs into PE curriculum. Other studies have found that that integrating aerobic training into PE results in improved behavioral selfregulation and classroom function improvements among children with behavioral issues, and so maybe a useful tool in PE classes serving children with Individualized Educational Plans for social, emotional or behavioral disabilities [22].

Incorporating $\mathrm{HITT}$ programming into $\mathrm{PE}$ curriculum in under resourced school districts can help promote improvements in PA levels within and beyond the traditional school day. Likewise, literature supports the value of HITT training in improving cardiorespiratory endurance, cognitive function, and academic improvements [18]. Although more research has supported these findings in adolescent youth, the current study supports the positive benefits of embedding an acute bout of HITT into PE curriculum on enhancing MVPA and potential improvements in academic achievement. Given these positive benefits on vulnerable children's PA and potential learning outcomes and the results of the current study, established PE curricula should consider incorporating such training into PE classes to provide students with enhanced opportunities to improve MVPA levels within the limited PE participation.

While a strength of the current study was its pragmatic design in a real-world setting, this approach has important limitations. Findings from the current study are limited by the lack of randomization among the control and intervention groups; randomizing the $3^{\text {rd }}$ and $4^{\text {th }}$ graders across all groups would eliminate the potential for confounding by grade level. Additionally, using only $3^{\text {rd }}$ and $4^{\text {th }}$ graders from one selected Lawrence Public School enrolled in the AAP may potentially impact the generalizability to other grades and settings. However, despite these limitations, the collection of objectively-measured PA was a strength of this study, as was the ability to test math assessment scores pre- and post-intervention and behavioral outcomes daily.

\section{Conclusion}

Implementing acute HITT programming into established PE curriculum may be an effective approach to improving MVPA and academic scores in school-aged children from under-resourced communities. This approach is feasible and leverages existing school resources; therefore, even underresourced school systems should consider implementing HITT into established PE during the traditional school day.

\section{References}

[1] D. Riebe, B. Franklin, P. Thompson, Updating ACSM's recommendations for exercise preparticipation health screening, Medicine and Science in Sport and Exercise, 47(11) (2015) 2473-2479. [DOI] [PubMed]

[2] D. Kibbe, J. Hackett, M. Hurley, A. MacFarland, K. Schubert, A, Schultz, S. Harris, Ten Years of TAKE 10 !(®): Integrating physical activity with academic concepts in elementary school classrooms. Preventative Medicine, 52(1) (2011) 43-50. [DOI] [PubMed]

[3] D. Castelli, C. Hillman, S. Buck, H. Erwin, Physical fitness and academic achievement in third- and fifth-grade students, Journal of Sport and Exercise Psychology, 29(2) (2007) 239-252. [DOI] [PubMed] 
[4] S. Andermo, M. Hallgren, T. Nguyen, S. Jonsson, S. Petersen, M. Friberg, A. Romgvist, B. Stubbs, L. Elinder, School-related physical activity interventions and mental health among children: a systematic review and meta-analysis, Sports Medicine, 25(6) (2020) 1-27. [DOI] [PubMed]

[5] S. Austin, K. Bauer, A. Patel, A. Prokup, Swimming upstream: faculty and staff members from urban middle school in low-income communities describe their experience implementing nutrition and physical activity initiatives, Preventing Chronic Disease, 3(2) (2006) 1-9. [PubMed]

[6] A. Faigenbaum, J. Bush, R. McLoone, M. Kreckel, A. Farrell, N. Ratamess, J. Kang, Benefits of strength and skill based training during primary school physical education, Journal of Strength and Conditioning Research, 29(5) (2015) 12551262. [DOI] [PubMed]

[7] S. Weihrauch-Blüher, S. Wiegand, Risk factors and implications of childhood obesity. Current Obesity Reports, 7(4) (2018) 254-259. [DOI] [PubMed]

[8] S. Costigan, N. Eather, R. Plotnikoff, C. Hillman, D. Lubans, High-intensity interval training for cognitive and mental health in adolescents, Medicine and Sport in Sports Exercise, 48(10) (2016), 1985-1993. [DOI] [PubMed]

[9] C. Basch, Healthier students are better learners: A missing link in school reforms to close the achievement gap, Journal of School Health, 81(10) (2011) 593-598. [DOI] [PubMed]

[10] K. Fiscella, H. Kitzman, Disparities in academic achievement and health: the intersection of child education and health policy, Pediatrics, 123(3) (2019) 1073-1080. [DOI] [PubMed]

[11] A. García-Hermoso, R. Ramírez-Campillo, M, Izquierdo, Is muscular fitness associated with future health benefits in children and adolescents? A systematic review and metaanalysis of longitudinal studies, Journal of Sports Medicine, 49(7) (2019) 1079-1094. [DOI] [PubMed]

[12] $\mathrm{CH}$. Wu, C. Karageorghis, CC Wang, CH. SC. Kao, TM. Hung, YK. Chang, Acute aerobic and resistance exercise on executive function: An ERP study, Journal of Science Medicine and Sport, 22(12) (2019) 367-372. [DOI]
[13] United States Census Bureau [Internet]. Quick Facts, Lawrence City, Massachusetts. [Published July 1, 2019. Accessed May 1, 2021]. Available from: https://www.census.gov

[14] R. Ullmann, E. Sleator, R. Sprague, A change of mind: The conners' abbreviated rating scales reconsidered, Journal of Abnormal Child Psychology, 13(1985), 553-565. [DOI] [PubMed]

[15] P. Freedson, J. Sirard, E. Debold, Calibration of the computer science and applications, Inc.(CSA) accelerometer, Medicine Science Sports and Exercise, 30(5) (1998) 777-781. [DOI] [PubMed]

[16] Centers for Disease Control and Prevention [Internet]. Prevalence of obesity among adults and youth: United States, (2017). Available from: http://www.cdc.gov/nchs

[17] D. Ginsberg, The importance of play in promoting healthy child development and maintaining strong parent-child bonds, Pediatrics, 119(1) (2007) 182-191. [DOI] [PubMed]

[18] World Health Organization [Internet]. Global Recommendations on Physical Activity for Health. Geneva, CH: World Health Organization; (2010) Available from: https://www.who.int/

[19] D. Lubans, J. Richards, C. Hillman, G. Faulkner, M. Beauchamp, M. Nilsson, P. Kelly, J. Smith, L. Raine, S. Biddle, Physical activity for cognitive and mental health in youth: a systematic review of mechanisms, Pediatrics, 38(3) (2016). [DOI] [PubMed]

[20] J. Best, Effects of physical activity on children's executive function: contributions of experimental research on aerobic exercise, Developmental Review, 30(4) (2010) 331-359. [DOI] [PubMed]

[21] C. Hansen, L. Stevens, J. Coast, Exercise duration and mood state: how much is enough to feel better?, Journal of Health Psychology, 20(2001) 267-275. [DOI] [PubMed]

[22] E. Anderson, J. Durstine, Physical activity, exercise, and chronic diseases: A brief review, Journal of Sport Health and Health Science, 1(2019) 3-10. [DOI] 


\title{
Acknowledgement
}

This study was made possible through generous funding by the New Balance Foundation. The authors would like to thank the dedicated teachers and administration in the Lawrence Public Schools, the Accelerations Academy, the Merrimack Valley YMCA, and the research assistants who made this study possible

\section{Funding}

This study was funded by the New Balance organization

\section{Authors Contribution}

Dr. Peacock - data collection, conceptualization, draft preparation; Dr. Finn - conceptualization; Dr. Bowling - study design, statistical analysis, interpretation of results. All the authors read and approved the final version of the draft.

\section{Ethics Approval}

Approval was sought from Merrimack College and Lawrence Public Schools

\section{Informed Consent}

Written consent was obtained from participants

\section{Availability of data and material}

No additional data are available.

\section{Conflict of interest}

The authors declare that they have no conflict of interest. Presentation of the results of the present study in this manuscript do not constitute endorsement by ACSM.

\section{Does this article screened for similarity?}

Yes

\author{
About The License \\ (C) The author(s) 2022. The text of this article is open \\ access and licensed under a Creative Commons \\ Attribution 4.0 International License
}

